\title{
Effect of Burdock Root and the Fermented Product on Alloxan-Induced Mouse Hyperglycemia
}

\author{
Wakana Doi ${ }^{1}$, Yumi Asada ${ }^{1}$, Ayaka Ohno ${ }^{1}$, Yoshiko Okuda ${ }^{1}$, Shota Masuda ${ }^{1}$, Ayano Matsumoto ${ }^{1}$, \\ Chihiro Mori ${ }^{1}$, Takaya Agarie ${ }^{1}$, Kohji Ishihara ${ }^{1}$, Takayuki Murakami ${ }^{2} \&$ Noriyoshi Masuoka $^{1}$ \\ ${ }^{1}$ Department of Life Science, Okayama University of Science, Kita-ku, Okayama, Japan \\ ${ }^{2}$ Ahjikan Co. Ltd., Nishi-ku, Hiroshima, Japan \\ Correspondence: Noriyoshi Masuoka, Department of Life Science, Okayama University of Science, 1-1 \\ Ridai-cho, Kita-ku, Okayama 700-0005, Japan. Tel: 81-86-256-9593. E-mail: masuokan@dls.ous.ac.jp
}

Received: February 14, 2015 Accepted: April 17, 2015 Online Published: April 22, 2015

doi:10.5539/jfr.v4n4p10 URL: http://dx.doi.org/10.5539/jfr.v4n4p10

\begin{abstract}
Backgrounds: We reported that feeding 5\% Asperagillus awamori-fermented burdock root diet was effective in preventing mouse hyperglycemia caused by alloxan.

Methods: Diets containing 5\% burdock roots were prepared from raw and Asperagillus awamori-fermented burdock root powders. Acatalasemic mice, having a quite low catalase activity in blood, and normal mice were fed these diets for 14 weeks, separately. Then, alloxan $(200 \mathrm{mg} / \mathrm{kg}$ of body weight) or PBS was intraperitoneally administrated to each mouse. After 5 day from the administration, blood glucose assay and glucose tolerance test were carried out, and then insulin, C-peptide and lipid peroxide in plasma were examined.

Results: Incidences of hyperglycemia in normal mice fed control, raw and fermented burdock root diets were 25 , 20 and $11 \%$, respectively, and these in acatalasemic mice were 73, 80 and $27 \%$. Insulin and C-peptide in plasma of mice fed raw burdock root diet or control diet were low compared to mice fed the fermented diet.

Conclusions: Intake of raw burdock root does not suppress the alloxan-induced hyperglycemia but the fermented burdock root does. It is suggested that Asperagillus awamori plays an important role for the prevention.
\end{abstract}

Keywords: Burdock root, hyperglycemia, insulin, oxidative stress, alloxan, Asperagillus awamori

\section{Introduction}

Diabetes mellitus is a syndrome characterized by hyperglycemia, more than a desirable level of glucose in blood (Taylor, 1995). The morbidity causes blindness, renal failure and amputation, and diabetes is a worldwide disease and one of the major causes of death. Alloxan is a diabetogenic drug for animals, and alloxan with reducing agents in the body generated reactive oxygen species. These species cause oxidative stress and selectively injure $\beta$-cells in the pancreas so as to cause hyperglycemia as like diabetes Type 1 (Szkudelski, 2001; Lenzen, 2008). In order prevent this hyperglycemia, many researchers challenged to find (or pursue) anti-hyperglycemic compounds or products (Oloyede, Bello, Ajiboye, \& Salawu, 2015; Perumal, Anaswara, Muthurama, \& Krishan, 2014). We noticed that Japanese burdock root, Artium lappa, is edible in Korea and Japan and contains a considerable amount of polyphenols such as chlorogenic acid, caffeoylquinic acid, hydroxycinnamoylquinic acids and related compounds (Maruta, Kawabata, \& Niki, 1995; Lin \& Harnly, 2008), and investigated the effect of Aspergillus awamori-fermented burdock root on hyperglycemia. When mice were fed the Aspergillus awamori-fermented diet, hyperglycemia induced by alloxan was ameliorated (Takemoto, Doi, Zukeran, Inoue, Ishihara, \& Masuoka, 2014) like as the intake of antioxidants. However, it is unclear whether raw burdock root is able to modulate alloxan-induced mouse hyperglycemia. In this study, we examined antioxidant activity of raw and the fermented burdock root powders and the effect of raw burdock root diet on alloxan-induced mouse hyperglycemia.

\section{Materials and Methods}

\subsection{Materials}

Male mice of the $\mathrm{C} 3 \mathrm{H} / \mathrm{AnL} \mathrm{CS}^{\mathrm{a}} \mathrm{CS}^{\mathrm{a}}$ (normal) and $\mathrm{C} 3 \mathrm{H} / \mathrm{AnL} \mathrm{CS}^{\mathrm{b}} \mathrm{CS}^{\mathrm{b}}$ (acatalasemia) strains established by 
Feinstein, Braun, and Howard (1967) were used. Animal experimental procedure was approved by the Ethics Review Committees for Animal Experimentation of Okayama University of Science. Mice were bred and maintained on a laboratory diet (CE-2 diet, Clea Japan, Tokyo) and water ad libitum until the start of the experiments. Catalase activity in the mouse erythrocytes was measured according to previous method (Masuoka, Wakimoto, Ubuka, \& Nakano, 1996) and calculated as the difference between the hydrogen peroxide removal rate by hemolysate and the rate $(0.73 \mu \mathrm{mol} / \mathrm{s} / \mathrm{g}$ of hemoglobin) by hemoglobin (Takemoto, Tanaka, Iwata, Nishihara, Ishihara, Wang, Ogino, Taniuchi, \& Masuoka 2009). Raw and fermented burdock root powders were prepared by Ahjikan Co. Ltd (Hiroshima, Japan) from burdock roots (harvested in Japan). Burdock roots were cut into small pieces and then dried using air drying oven at $50{ }^{\circ} \mathrm{C}$ for $4 \mathrm{hrs}$ (raw burdock root powders). The dried pieces were mixed with an equal amount of water and $0.1 \%$ Aspergillus awamori spores (final concentration, w/w) and the mixture was fermented at $35^{\circ} \mathrm{C}$ for $40 \mathrm{hrs}$ (Aspergillus awamori-fermented burdock root powders) (Okazaki, Sitanggang, Sato, Ohnishi, Inoue, Iguchi, Watanabe, Tomotake, Harada, \& Kato, 2013). Control diet was AIN-93M (Reeves, Nielson, \& Fahey, 1993) and each burdock root diet contained 5\% burdock root powders was prepared according to the composition, which was indicated in Table 1. Pellets of these diets $(1.3 \mathrm{~cm})$ were prepared and stored at $-20^{\circ} \mathrm{C}$ until use.

Table 1. Composition of diets $(\%, w / w)$

\begin{tabular}{llll}
\hline Component & Control diet & Raw burdock root diet & Fermented burdock root diet \\
\hline Corn starch & 46.5692 & 41.5692 & 41.5692 \\
Milk casein & 14.0 & 14.0 & 14.0 \\
a-Corn starch & 15.5 & 15.5 & 15.5 \\
Sucrose & 10.0 & 10.0 & 10.0 \\
Soybean oil & 4.0 & 4.0 & 4.0 \\
Cellulose powders & 5.0 & 5.0 & 5.0 \\
Mineral mixture (AIN-93M) & 3.5 & 3.5 & 3.5 \\
Vitamin mixture (AIN-93VX) & 1.0 & 1.0 & 1.0 \\
L-Cystine & 0.18 & 0.18 & 0.18 \\
Choline & 0.25 & 0.25 & 0.25 \\
t-Butylhydroxyquinone & 0.00008 & 0.00008 & 0.00008 \\
Dried burdock root powders & 0.0 & 5.0 & 0.0 \\
Fermented burdock root powders & 0.0 & 0.0 & 5.0 \\
\hline Total (\%) & 100.0 & 100.0 & 100.0
\end{tabular}

Control diet is AIN-93M diet. Raw burdock root diet is $5 \%$ raw burdock root diet. Fermented burdock root diet is 5\% Aspergillus awamori-fermented burdock root diet.

\subsection{Antioxidant Activity in Raw and Aspergillus awamori-Fermented Burdock Root Powders}

\subsubsection{Extraction of Raw and Fermented Burdock Root Powders}

Five gram of each burdock root powders was extracted five-times with $25 \mathrm{~mL}$ of aqueous $50 \%$ methanol for $1 \mathrm{~h}$. The extracts were gathered and evaporated at $40{ }^{\circ} \mathrm{C}$. The residue was dissolved with $10 \mathrm{~mL}$ of $50 \%$ methanol in water, and the solution was used as sample.

\subsubsection{Radical Scavenging Activity on DPPH}

Sample $(0.03 \mathrm{~mL})$ was added to the mixture consisted of $1.00 \mathrm{~mL}$ of $100 \mathrm{mM}$ acetate buffer $(\mathrm{pH} 5.5), 1.87 \mathrm{~mL}$ of ethanol and $0.10 \mathrm{~mL}$ of ethanolic solution of $3 \mathrm{mM}$ DPPH at $25{ }^{\circ} \mathrm{C}$. The absorbance at $517 \mathrm{~nm}$ (DPPH, $\varepsilon$ $=8.32 \times 10^{3}$ ) was recorded for $20 \mathrm{~min}$ (Blois, 1958). From decrease of the absorbance, scavenging activity was calculated and expressed as scavenged DPPH molecules per $1.0 \mathrm{~g}$ of powders.

\subsubsection{Determination of Polyphenol Contents}

Polyphenol contents in samples were determined by the method reported by Naser, Ayed and Metche (1996). 
Sample $(0.2 \mathrm{~mL})$ was added to the mixture of $0.2 \mathrm{~mL}$ of Folin-Ciocalteau's phenol regent and $4 \mathrm{~mL}$ of water, and the mixture was reacted $8 \mathrm{~min}$. Then, $0.6 \mathrm{~mL}$ of $7 \%$ sodium carbonate aqueous solution was added to the mixture, and the mixture was reacted at $40{ }^{\circ} \mathrm{C}$ for $30 \mathrm{~min}$. Absorbance at $570 \mathrm{~nm}$ was recorded. Gallic acid was used as standard compound, and polyphenol content was expressed as amounts of gallic acid.

\subsection{Animal Experiments}

Acatalasemic mice $(\mathrm{n}=48)$ and normal mice $(\mathrm{n}=48)$ were used at the age of 14 to 15 weeks old (body weight was between 25 and $36 \mathrm{~g}$ ) and were housed in a group of four. Acatalasemic and normal mice were divided into three kinds of diet groups, respectively. Control diet, raw and fermented burdock root diets were fed ad libitum for 14 weeks. Then, each diet group further divided two groups. Alloxan $(200 \mathrm{mg} / \mathrm{kg}$ of body weight) was intraperitoneally administrated using $0.106 \mathrm{M}$ alloxan in phosphate buffered saline (PBS) to each mouse in a group (Kamimura et al., 2013), and the same volume of PBS was injected to each mouse in another group as control. Mice in each group were maintained on the same diet for one more week. After five days from alloxan (or PBS) administration, mice were fasted for $20 \mathrm{hrs,} \mathrm{and} \mathrm{blood} \mathrm{glucose} \mathrm{assay} \mathrm{and} \mathrm{glucose} \mathrm{tolerance} \mathrm{test} \mathrm{(GTT)}$ were carried out. After 2 days from the assay and GTT, mice were fasted for $20 \mathrm{hrs}$ and were killed. Under diethyl ether anesthesia, each mouse blood was collected in test tube containing heparin as the anticoagulant from heart. Then, pancreas in each mouse was isolated, and the sections were prepared for microscopic studies. Blood was centrifuged and the plasma was isolated. Oxidative stress marker, as well as the insulin and C-peptide levels in plasma, was examined.

\subsection{Assay of Blood Glucose}

After fasting for $20 \mathrm{hrs}$, glucose content in the blood obtained from the tail was determined. As the blood volume for the determination of blood glucose was quite small (approximately $2 \mu \mathrm{L}$ ), the glucose contents in blood were measured with a "Glucose-Test-Ace R" apparatus (Sanwa Kagaku Kenkyusho Co., Nagoya, Japan) applying a glucose oxidase method.

\subsection{Glucose Tolerance Test (GTT)}

After fasting for $20 \mathrm{hrs}$, a forty percent aqueous glucose solution ( $5 \mathrm{~mL} / \mathrm{kg}$ of body weight) was intraperitoneally administered to each mouse (Gao et al., 2007). At 0 and $30 \mathrm{~min}$ before and 15, 30, 60, 90 and $120 \mathrm{~min}$ after the administration, glucose contents in the blood were measured.

\subsection{Measurement of Lipid Peroxide in Plasma}

Lipid peroxidation in plasma was determined using a Bioxytech LPO-586 KIT (OXIS Health Products Inc, CA, USA). Malondialdehyde and 4-hydroxyalkenals as products of lipid peroxidation were reacted with $\mathrm{N}$-methyl-2-phenylindole at $45{ }^{\circ} \mathrm{C}$. The absorbance at $586 \mathrm{~nm}$ was recorded. Values of lipid peroxide in blood were calculated as malondialdehyde.

\subsection{Determination of the Insulin and C-peptide Levels in Blood}

The insulin and C-peptide plasma levels were determined using Mouse Insulin and C-peptide ELISA KITs (U-type) (Shibayagi Co. Ltd., Gunma, Japan). Each determination was carried out according to the manufacturer's instructions. Biotin-conjugated anti-insulin antibody $(45 \mu \mathrm{L})$ was added to each well in an antibody-coated 96-well plate. To the well, $5 \mu \mathrm{L}$ of the sample or standard solution was added and reacted for 2 hrs. Then $50 \mu \mathrm{L}$ of peroxidase-conjugated avidin solution was added and reacted for $30 \mathrm{~min}$. Chromogenic substrate solution $(50 \mu \mathrm{L})$ was added and reacted for $30 \mathrm{~min}$. The reaction was stopped and the absorbance at $450 \mathrm{~nm}$ (sub-wave length, $620 \mathrm{~nm}$ ) was recorded.

\subsection{Microscopic Studies of Pancreatic Tissues in the Mice Treated With Alloxan}

Isolated pancreatic tissues were fixed in Bouin's fluid and embedded in paraffin. Serial sections $(6 \mu \mathrm{m})$ were cut from each paraffin-embedded tissue block, and several sections were stained with hematoxylin-eosin and mouse anti-insulin antibody (Santa Cruz Biotechnology) using the Vectastain Elite ABC Rabbit IgG Kit for visualization by light microscopy. The islets and other cells were recorded with a FX380 CCD Camera and a microscope (Olympus, Tokyo, Japan).

\subsection{Statistical Analysis}

Student's t-test (unpaired) was used to evaluate the statistical significance of difference. The difference was considered significant when $\mathrm{p}<0.05$. 


\section{Results}

\subsection{Catalase Activity in Mouse Blood}

The catalase activity of acatalasemic mice in blood at $25{ }^{\circ} \mathrm{C}$ was $0.15 \pm 0.07 \mu \mathrm{mol} / \mathrm{s} / \mathrm{g}$ of $\mathrm{Hb}$, and that of normal mice was $6.77 \pm 0.62 \mu \mathrm{mol} / \mathrm{s} / \mathrm{g}$ of $\mathrm{Hb}$. $(\mathrm{p}<0.001)$

\subsection{Antioxidant Activities of Burdock Root Products}

DPPH scavenging activities and polyphenol contents in raw and fermented burdock root were examined. The DPPH scavenging activity in raw and fermented burdock powders was $9.0 \pm 1.6$ and $87.6 \pm 3.2 \mu \mathrm{mol} / \mathrm{g}$, respectively, and polyphenol contents was $1.6 \pm 0.1$ and $7.0 \pm 0.4 \mathrm{mg} / \mathrm{g}$. After fermentation, both polyphenol contents and DPPH scavenging activities increased $(\mathrm{p}<0.001)$.

\subsection{Blood Glucose in the Mice Maintained on the Burdock and the Control Diets Before and After Alloxan Administration}

Average fasting blood glucose in the normal and acatalasemic mice was $81 \pm 20 \mathrm{mg} / \mathrm{dL}$. After alloxan or PBS administration, the average fasting blood glucose was indicated in Figure 1. Blood glucose in acatalasemic mice was higher than that in normal mice after alloxan administration. Furthermore, the average fasting blood glucose of acatalasemic mice fed the control and raw burdock root diets was significantly higher than that of PBS-injected mice $(\mathrm{p}<0.02)$.

Incidence of hyperglycemia was indicated in Table 2, and the incidence in both mice fed fermented burdock diet was lower than that fed the control and raw burdock root diets.

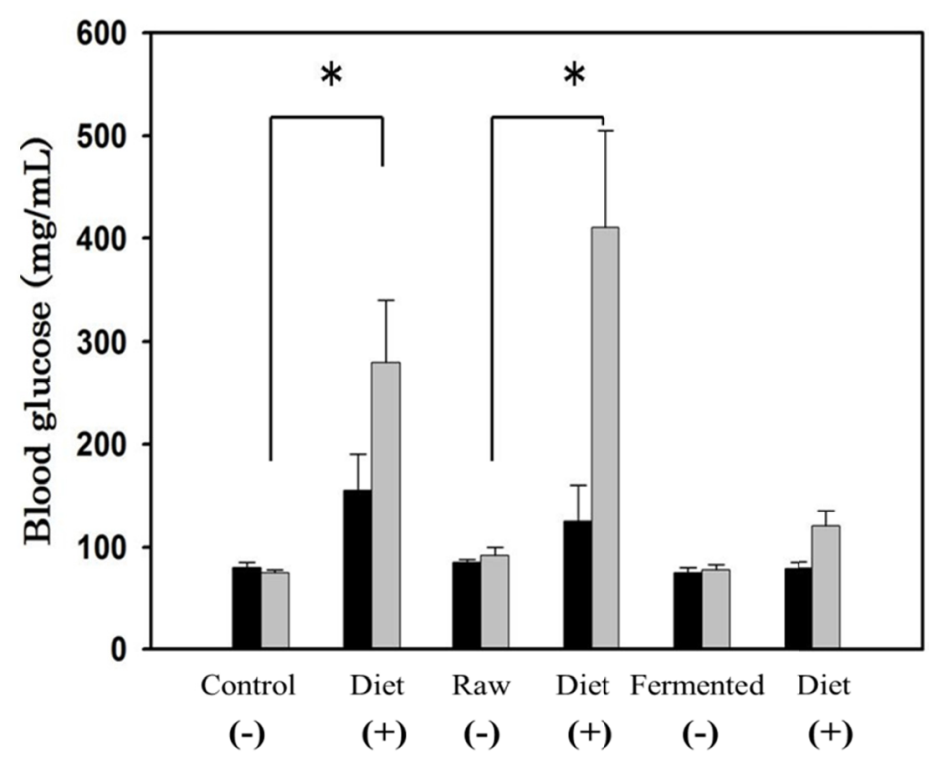

Figure 1. Blood glucose after 5 days from alloxan administration

Mice fed a control (AIN-93M) diet, raw burdock diet or fermented burdock diet for 14 weeks. Then, alloxan was administrated. (+) indicated alloxan administrated group, (-) did PBS group. Blood glucose of normal mice indicated black column, and gray column did that of acatalasemic mice. Vertical lines indicate SE. * indicates $\mathrm{p}$ $<0.02$. 
Table 2. Incidence of hyperglycemia after alloxan administration

\begin{tabular}{lllll}
\hline \multirow{2}{*}{ Mice } & $\begin{array}{l}\text { Alloxan } \\
(\mathrm{mg} / \mathrm{kg})\end{array}$ & \multicolumn{2}{l}{ Incidence of hyperglycemia \% } \\
\cline { 3 - 5 } & 0 & Control diet $(\mathrm{n})$ & Raw diet $(\mathrm{n})$ & Fermented diet $(\mathrm{n})$ \\
\hline Normal & 200 & $25(20)$ & $0(8)$ & $0(8)$ \\
Normal & 0 & $0(8)$ & $20(20)$ & $11(18)$ \\
Acatalasemia & 200 & $73(22)$ & $0(8)$ & $0(8)$ \\
Acatalasemia & 200 & $80(20)$ & $27(22)$ \\
\hline
\end{tabular}

" $n$ " in parentheses indicates number of mice. Hyperglycemia is $>121 \mathrm{mg} / \mathrm{dl}$ of blood.

\subsection{Effect of the Burdock or the Control Diet on GTT}

GTTs were indicated in Figure 2. Blood glucose in the mice fed the control or raw burdock diets at 30, 60, 90 and $120 \mathrm{~min}$ from glucose administration was higher than mice fed the fermented burdock diet. Blood glucose in the acatalasemic mice fed the control diet or raw burdock diet after 120 min was higher than that before glucose administration.
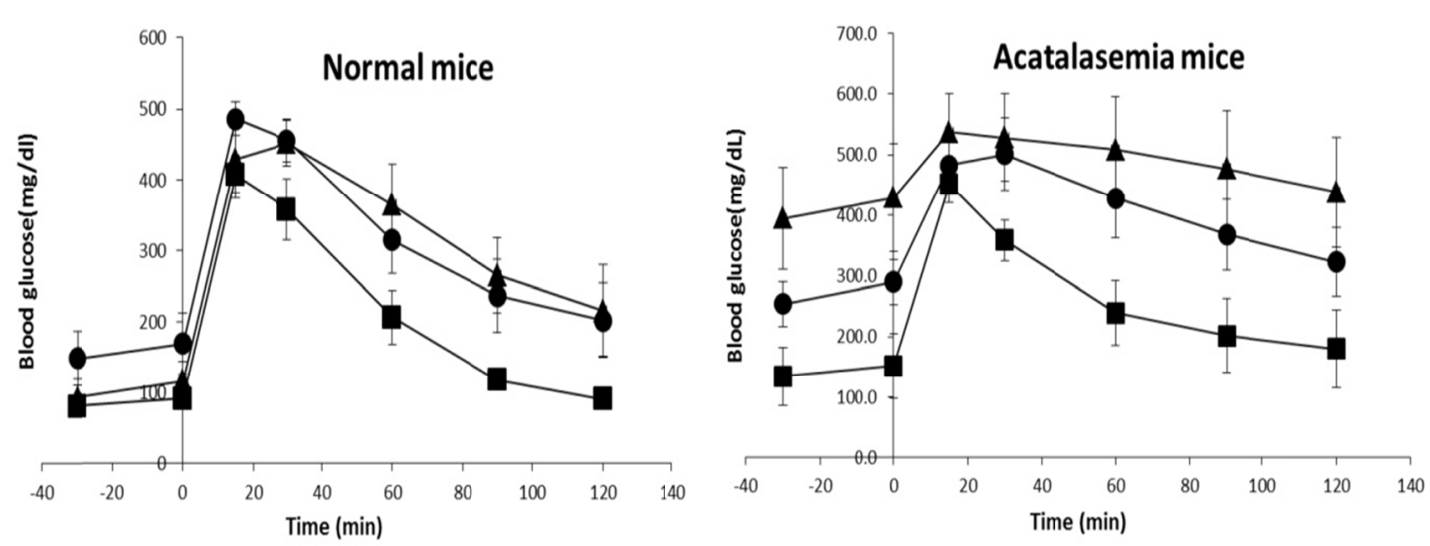

Figure 2. Glucose tolerance tests of alloxan administrated mice

Acatalacemic mice fed raw diet, fermented diet or the control diet for 14 weeks. Glucose tolerance test was carried out after 5 days from alloxan administration. Glucose was loaded at 0 min. Triangles $(n=7)$; mice fed raw burdock root diet, squared $(\mathrm{n}=7)$; mice fed fermented burdock root diet, circles $(\mathrm{n}=8)$; mice fed control diet. Vertical lines indicate SE.

\subsection{Lipid Peroxide Marker in Plasma Before and After Alloxan Treatment}

After alloxan administration, lipid peroxide in blood of mice increased. Compared to the increase of acatalasemic mice fed control diet, increase of the mice fed raw burdock diet was a same level, but that fed fermented burdock root diet was slightly low (data not indicated).

\subsection{Insulin and C-peptide Concentrations}

Insulin concentration in blood became low after alloxan administration. After 7 days from alloxan administration, insulin concentrations of normal mice fed the control and raw burdock diets were $230 \pm 30$ and $170 \pm 30 \mathrm{pg} / \mathrm{mL}$, respectively, and lower than the mice fed the fermented burdock diet $(360 \pm 60 \mathrm{pg} / \mathrm{mL})$. Insulin concentrations of acatalasemic mice fed the control and raw burdock diets were $110 \pm 18,111 \pm 77 \mathrm{pg} / \mathrm{mL}$ and lower than the mice fed fermented burdock diet $(224 \pm 61 \mathrm{pg} / \mathrm{mL})$. C-Peptide concentrations in fasting blood also became low after alloxan administration, and the C-peptide level in the normal mouse blood was higher than that in the acatalasemic blood. The levels of mice fed control, raw and fermented burdock root diets changed as like insulin levels in blood. 


\subsection{Microscopic Examination of Pancreatic Tissues in the Acatalasemic Mice Treated With Alloxan}

Pancreatic tissues after alloxan administration were subjected to immunohistochemical staining of anti-insulin antibody. In normal mice, there was scarcely difference of the numbers among the mice fed raw, fermented burdock root diets and the control one before and after alloxan administration (data not shown). However, in acatalasemic mice, there is a significant difference between the fermented diet and other diets after alloxan administration (Figure 3).

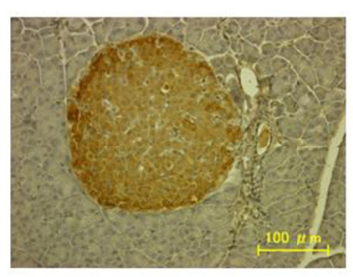

A (-)

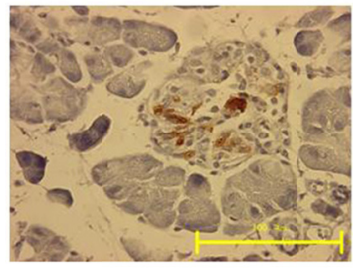

$\mathrm{A}(+)$

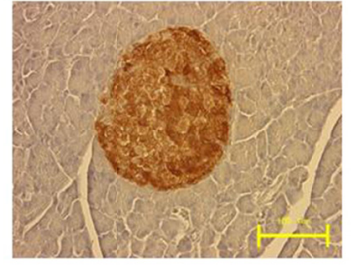

B (-)

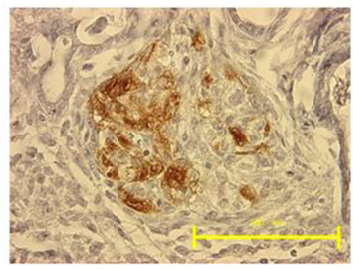

$\mathrm{B}(+)$

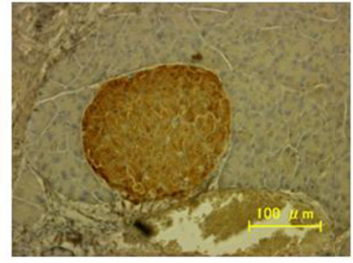

C (-)

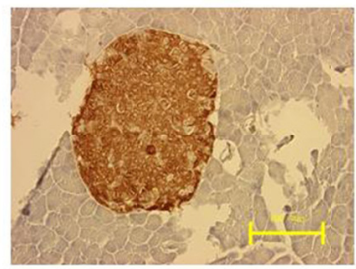

$\mathrm{C}(+)$

Figure 3. Acatalasemic mouse pancreas stained with insulin-antibody after alloxan administration

Acatalasemic mice fed raw burdock diet, the fermented one or the control diet for 14 weeks. Then, alloxan or PBS was administrated. After a week, mouse pancreas was isolated and stained with insulin-antibody. (A) From mice fed control diet; (B) From mice fed raw burdock diet; (C) From mice fed fermented burdock diet. (+)indicates alloxan administration, (-) indicates PBS.

\section{Discussion}

In previous study (Takemoto, Tanaka, Iwata, Nishihara, Ishihara, Wang, Ogino, Taniuchi, \& Masuoka 2009), alloxan administration to mice indicated that incidence of hyperglycemia in acatalasemic mice was higher than that in normal mice. It indicates that acatalasemic mice are more susceptible than normal mice to alloxan induced hyperglycemia. When mice fed Aspergillus awamori-fermented burdock diet, incidence of hyperglycemia in normal and acatalasemic mice was lower than that in mice fed the control diet after alloxan administration and the low insulin in blood was improved as previously reported (Takemoto, Doi, Zukeran, Inoue, Ishihara, \& Masuoka, 2014).

In this study, we prepared raw and fermented burdock root diets and examined the difference of feeding between raw and fermented burdock diets for hyperglycemia caused by alloxan administration to make clear whether fermentation of the burdock root with Aspergillus awamori is necessary or not to ameliorate the hyperglycemia, Feeding of the raw burdock diet did not suppress the incidence of hyperglycemia and did not improve GTT compared to the control. Lipid peroxide level in blood was same as feeding of control diet. Insulin concentration in blood decreased and was same level as the control diet. These results indicated that hyperglycemia and low insulin concentration induced by alloxan administration were not ameliorated by feeding of raw burdock root diet but were by feeding of the fermented burdock diet. It suggests that fermentation with Asperagillus awamori plays an important role for the anti-hyperglycemia activity.

As we supposed that oxidative stress was prevented by intake of antioxidants (Yamaoka, Kim, Ogihara, Oue, Takitani, Yoshida \& Tamai, 2008; Choi, Bae, Yu, Youn, \& Sung, 2009), DPPH scavenging activity and polyphenol content were examined. By the fermentation, increase of DPPH scavenging activity, which correlated increase of polyphenol content, in burdock root powders was observed. The result suggests that increase of the activity with Asperagillus awamori fermentation ameliorates hyperglycemia as the activity scavenges oxidative 
radical species induced with alloxan. Recently, El-Deep et al. (2014) reported that intake of Asperagillus awamori of chickens under high ambient temperature improved the growth and induced increase of $\alpha$-tocopherol (vitamin E) level in their muscles. As intake of vitamin E improved mouse hyperglycemia caused by alloxan (Kamimura et al., 2013), further study is currently underway.

\section{Conclusion}

Japanese burdock root is taken as a vegetable in Japan. Raw burdock root does not indicate anti-hyperglycemia caused by oxidative stress but the product fermented with Asperagillus awamori indicates anti-hyperglycemia activity. It is deduced that intake of the fermented burdock root product is useful in preventing hyperglycemia caused by oxidative stress.

\section{References}

Blois, M. S. (1958). Antioxidant determinations by the use of a stable free radical, Nature, 181, 1199-1200. http://dx.doi.org/10.1038/1811199a0

Choi, E. J., Bae, S. C., Yu, R., Youn, J., \& Sung, M. K. (2009). Dietary vitamin E and quercetin modulate inflammatory responses of collagen-induced arthritis in mice. J. Med. Food, 12, 770-775. http://dx.doi.org/10.1089/jmf.2008.1246

El-Deep, M. H., Ijiri, D., Eid, Y. Z., Yamanaka, H., \& Ohtsuka, A. (2014). Effects of dietary Supplementation with Aspergillus Awamori on Growth performance and antioxidative status of broiler chickens exposed to high ambient temperature. Japan Poultry Science Association, 51, 281-288. http://dx.doi.org/10.2141/2013/jpsa.0130154

Feinstein, R. N., Braun, J. T., \& Howard, J. B. (1967). Acatalasemic and hypocathalasemic mouse mutants. II. Mutational variations in blood and solid tissue catalases. Arch. Biochem. Biophys., 120, 165-9. http://dx.doi.org/10.1016/0003-9861(67)90609-1

Gao, D., Li, Q., Liu, Z., Li, Y., Liu, Z., Fan, Y., ... Li, J. (2007). Hypoglycemic effects and mechanisms of action of Cortex Lycii Radicis on alloxan-induced diabetic mice. Yakugaku Zasshi, 127, 1715-1721. http://dx.doi.org/10.1248/yakushi.127.1715

Kamimura, W., Doi, W., Takemoto, K., Ishihara, K., Wang, D.H., Sugiyama, H., Oda, S., \& Masuoka, N. (2013). Effect of vitamin $\mathrm{E}$ on alloxan-induced mouse diabetes. Clin. Biochem., 46, 795-798. http://dx.doi.org/10.1016/j.clinbiochem.2013.02.016

Lenzen, S. (2008). The mechanisms of alloxan- and streptozotocin-induced diabetes. Diabetologia, 51, 216-226. http://dx.doi.org/10.1007/s00125-007-0886-7

Lin, L-Z., \& Harnly, J. M. (2008). Identification of hydroxycinnamoylquinic acids of arnica flowers and burdock roots using a standardized LC-DAD-ESI/MS profiling method. J. Agric. Food Chem., 56, 10105-10114. http://dx.doi.org/10.1021/jf802412m

Maruta, Y., Kawabata, J., \& Niki, R. (1995). Antioxidative caffeoylquinic acid derivatives in the roots of burdock (Arctium lappa L.). J. Agric. Food Chem., 43, 2592-2595. http://dx.doi.org/10.1021/jf00058a007

Masuoka, N., Wakimoto, M., Ubuka, T., \& Nakano, T. (1996). Spectrophotometric determination of hydrogen peroxide: catalase activity and rates of hydrogen peroxide removal by erythrocytes. Clin. Chim. Acta, 254, 101-112. http://dx.doi.org/10.1016/0009-8981(96)06374-7

Nasr, C. B., Ayed, N., \& Metche, M. (1996). Quantitative determination of the polyphenolic content of pomegranate peel. Z. Lebensm Unters Forsch., 203, 374-378. http://dx.doi.org/10.1007/BF01231077

Okazaki, Y., Sitanggang, N. V., Sato, S., Ohnishi, N., Inoue, J., Iguchi, T., ... Kato, N. (2013). Burdock fermented by Aspergillus awamori elevates cecum Bifidobacterium, and reduces fecal deoxycholic acid and adipose tissue weight in rats fed a high-fat diet. Biosci. Biotechnol. Biochem., 77, 53-57. http://dx.doi.org/10.1271/bbb.120551

Oloyede, H. O., Bello, T. O., Ajiboye, T. O., \& Salawu, M. O. (2015). Antidiabetic and antidyslipidemic activities of aqueous leaf extract of Dioscoreophyllum cumminsii (Stapf) Diels in alloxan-induced diabetic rats. J. Ethnophamacol., 166, 313-322. http://dx.doi.org/10.1016/j.jep2015.02.049

Perumal, P. S., Anaswara, P. V., Muthurama, A., \& Krishan, S. (2014) Therapeutic potency of saponin rich aqueous extract of Scoparia dulcis L. in alloxan induced diabetes in rats. Pharmacological Study, 35(2), 211-217. http://dx.doi.org/10.4103/0974-8520.146261 
Reeves, P. G., Nielson, F. H., \& Fahey, G. C. Jr. (1993). AIN-93 purified diets for laboratory rodents: final report of the American Institute of Nutrition and hoc writing committee on the reformulation of the AIN-73A rodent diet. J. Nutr., 123, 1939-1951.

Szkudelski, T. (2001). The mechanism of alloxan and streptozotocin action in B cells of the rat pancreas. Physiol. Res., 50, 536-546.

Takemoto, K., Doi, W., Zukeran, A., Inoue, J., Ishihara, K., \& Masuoka, N. (2014). Effect of Aspergillus awamori-fermented burdock root on mouse diabetes induced by alloxan -prevention of cell apoptosis. Food and Nutrition Science, 5, 1554-1560. http://dx.doi.org/10.4236/fns.2014.516168

Takemoto, K., Tanaka, M., Iwata, H., Nishihara, R., Ishihara, K, Wang, D. H., .. Masuoka, N. (2009), Low catalase activity in blood is associated with the diabetes caused by alloxan. Clin. Chim. Acta, 407, 43-46. http://dx.doi.org/10.1016/j.cca.2009.06.028

Taylor, S. I. (1995). Diabetes Mellitus. In C. R. Scriver, A. L. Beaudet, W. S. Sly \& D. Valle (Eds.) The metabolic and molecular bases of inherited disease Seventh edition (pp. 843-896). McGrew-Hill, NY.

Yamaoka, S., Kim, H. S., Ogihara, T., Oue, S., Takitani, K., Yoshida, Y., \& Tamai, H. (2008). Severe vitamin E deficiency exacerbates acute hyperoxic lung injury associated with increased oxidative stress and inflammation. Free Radic. Res., 42, 602-612. http://dx.doi.org/10.1080/10715760802189864

\section{Copyrights}

Copyright for this article is retained by the author(s), with first publication rights granted to the journal.

This is an open-access article distributed under the terms and conditions of the Creative Commons Attribution license (http://creativecommons.org/licenses/by/3.0/). 